\section{Protokoll der Mitgliederversammlung auf dem DLT in Stuttgart am 10.10.13}

Der Vorsitzende Frentzel-Beyme eröffnet die Versammlung. Die Einladung ist rechtzeitig an alle Mitglieder gegangen.

1. Das Protokoll der letzten MV von Davos 2012 wird genehmigt.

2. Die Sitzung beginnt mit einer Gedenkminute für das Ehrenmitglied Richard Soldner, Erfinder und Erbauer des weltersten Real-time US-Geräts, des Vidoson. Soldner war bis zu seinem Tod aktiv und arbeitete äußerst kompetent im Museumsrat mit. Er wird uns sehr fehlen.

3. Bericht des Vorsitzenden:

- Der Film über die Geschichte der Ultraschalldiagnostik ist insgesamt sehr gut angekommen. Er wurde ca. 140-mal angefordert und wurde auch an die ÖGUM und an die EFSUMB verkauft. Der Film für Laien ist auch auf der Website der DEGUM eingestellt.

> Der Museumsrat gestaltete seine Internet-Seiten neu; sie sind jetzt auch komplett ins Englische übersetzt.

- Unsere 3 Kretz Combison-Geräte aus dem Jahr 1977 sind alle repariert worden. Unser Techniker Herr Lange hat das Vidoson und das SAL 20 von Toshiba repariert.

- Auf dem DLT in Stuttgart hat der Museumsrat 2 Sitzungen organisiert, die Laudatio-Sitzung für zu Ehrende zusammengestellt und in einer Arbeitssitzung die Aufarbeitung der europäischen Geschichte des US in der Medizin initiiert.

- Die Bibliothek wurde jetzt im Lager eingerichtet.
- Als nächstes werden wir die Geschichte der DAUD und der DEGUM erforschen und unsere Ausstellung neu gestalten, indem wir von der Beschilderung der Einzelstücke dazu übergehen, geschichtliche Linien darzustellen.

4. Im Jahr 2012 betrugen die Ausgaben ca. $8000 €$ und Einnahmen ca. 9000 $€$. Der momentane Kontostand beträgt ca. $8000 €$.

5. Der Antrag auf Entlastung des Vorstandes wird einstimmig angenommen.

6. Bei der Wahl des Museumsrates wurde der alte einstimmig ohne Gegenstimmen wiedergewählt mit den Herren Frentzel-Beyme (Vorsitzender), Christian Jakobeit (stellvertretender Vorsitzender), Harald Lutz, Manfred Salaschek und Dieter Nürnberg.

7. Da zum Punkt Varia keine weiteren Wortmeldungen kommen, beschließt der Vorsitzende die Versammlung.

Protokoll: Frentzel-Beyme 